\title{
Higher Brain Dysfunction after Traumatic Brain Injury in School-aged Children: Review of the Literature
}

\section{Masaru Oga*}

Department of Neurosurgery, Tokyo Metropolitan Ohtsuka Hospital, Japan

\begin{abstract}
Higher brain dysfunction after traumatic brain injury in school-aged children potentially have serious impact on their lives than adults, because children are on their developmental way to be mature adults under the environment they should learn various knowledge and skills. Neuropsychological, psychosocial, and academic conditions/outcomes are evaluated by appropriate tools and methods for them. Medical care and support are planned on the basis of their conditions and modified with time in response to their outcomes. Cognitive rehabilitation has been developing to contribute the recovery from their impairment and return to school through four major tactics; improvement of higher brain dysfunction itself, acquirement of compensatory maneuvers/adjustment of environment, support for re-entry to school or finding employment, and acceleration for understanding or acceptance of impairment to people concerned including parents. The number of highly qualified study such as randomized clinical trial or meta-analytic clinical research is still few especially in Japan while developing basic research with a focus on neuroimaging is contributing to the clinical attempt. The issues related to concussion or post-concussion syndrome would be more and more attention in the future.
\end{abstract}

Keywords: Traumatic brain injury; Higher brain dysfunction; Children; School age

\section{Introduction}

In Japan, according to the vital statistics by Ministry of Health, Labour and Welfare, "unexpected accident" has been keeping the top three as a cause of mortality in children in recent years [1]. Consumer affairs agency also reported in 2013 that the traffic accident and fall, in most of which Traumatic Brain Injury (TBI) induced fatal damage, accounted for $35 \%$ in mortality caused by unexpected accident (under 9 years old) [2]. Although the number of traffic accidents and number of mortality caused by TBI have declined year after year by development of preventive measures against traffic accident, progress in emergency medical care and upgrading of road traffic law, the population of children under 15 years old (16.17 million in April 1,2015) has declined at 34 years in a row according to report of Statistics Bureau, Ministry of Internal Affairs and Communications [3]. Furthermore, World Population Prospects by United Nations reports that the population ratio of children in Japan is expected to remain $12 \%$ until 2100 [4].

Considering the situation in Japan as described above, the future role of children as supporters of our country in coming aging society is indispensable and therefore the trial of return to school and society for children with TBI is also one of the important subjects in Japan.

In this article higher brain dysfunction after traumatic brain injury in school-aged children is focused and reviewed, comparing reports of home and abroad.

\section{The Characteristics of Recovery Process after TBI in Children from the Point of Higher Brain Dysfunction}

There are two major salient differences between children and adults in the recovery process of higher brain dysfunction after TBI. Primarily children need to develop various social skills, not only learning academic knowledge, to be grown up as healthy members of society. In the second, recovery goal for children with TBI, rather than reaching plateau in case of adults, should be how they catch up with the normal growth and maintain it. The first characteristic suggests which outcomes we should select in the evaluation of higher brain dysfunction after TBI. The second characteristic suggests when we should appropriately evaluate outcomes described in the first one.

\section{Which Outcomes we should select in the Evaluation of Higher Brain Dysfunction after TBI in School-aged Children?}

Basically GOS (Glasgow Outcome Scale) [5] and/or FIM (Functional Independent Measure) [6], only evaluative tools in case of severely disabled in communication, are applied to evaluate functional status and ADL [7]. To those whom we can communicate, three outcomes neuropsychological, psychosocial and academic are usually evaluated.

Neuropsychological outcome is essential to evaluate higher brain dysfunction after TBI and composed of intellectual quotient, memory, attention, executive function, theory of mind, and so on. Unfortunately, in evaluation of neuropsychological outcome for children, we have few standardized tests such as WISC [8] for intellectual quotient, and other standardized tests, for example, DN-CAS [9] for attention and executive function, are not widely used.

Psychosocial outcome is intended to evaluate soundness of relationship between person and society, composed of behavior disturbance such as ADHD (Attention-Deficit Hyperactivity Disorder), personality change, antisocial behavior, emotional disorder such as PTSD (Post-Traumatic Stress Disorder), adaptive dysfunction, burden of caregiver such as parents, and so on. There are a little bit too many semi-quantitative scales and questionnaires; Behavior Rating Inventory of Executive Function (BRIEF) [10], Child Behavior Checklist (CBCL) [11], Diagnostic Interview for Children and Adolescents (DICA) [12], the Schedule for Affective Disorders and Schizophrenia for SchoolAge Children-Present(K-SADS-P) [13], Neuropsychiatric Rating Scale

*Corresponding author: Masaru Oga, Department of Neurosurgery, Tokyo Metropolitan Ohtsuka Hospital, University of Minnesota, Minamiohtsuka2-8-1, Toshima-ku, Tokyo, Japan, Tel: +81-03-3941-3211; E-mail: masaru_oga@tmhp.jp

Received June 16, 2018; Accepted July 24, 2018; Published July 31, 2018

Citation: Oga M (2018) Higher Brain Dysfunction after Traumatic Brain Injury in School-aged Children: Review of the Literature. Int J Neurorehabilitation 5: 326. doi: 10.4172/2376-0281.1000326

Copyright: $\odot 2018$ Oga M. This is an open-access article distributed under the terms of the Creative Commons Attribution License, which permits unrestricted use, distribution, and reproduction in any medium, provided the original author and source are credited. 
(NPRS) [14] and Post-Injury Symptom Checklist [15] to behavioral and emotional disorder; Vineland Adaptive Behavior Scale (VABS) [16] to adaptive disorder; Family Assessment Device (FAD) [17], the Family Burden of Injury Interview (FBII) [18], and Brief Symptom Inventory (BSI) [19] to caregiver outcome, to perform strict meta-analysis because each group in each country use each scale respectively.

In academic outcome, propriety and period of return to school, transition of academic achievement and drop-out or not are mainly evaluated [20-23]. Especially language ability is emphasized in academic achievement and evaluated by the Clinical Evaluation of Language Fundamentals (CELF) [24,25]. As to employment, being on the extension of academic outcome, socioeconomically status is discussed as a landmark of QOL overseas [26], whereas cost-effectiveness of rehabilitation to the grade of social recovery is discussed in Japan [27].

\section{When we should Appropriately Evaluate Outcomes of Higher Brain Dysfunction after TBI in School-aged Children?}

Two systemic reviews of pediatric mild TBI $[28,29]$ follow the cases up to three years and most of the cases sufficiently recover within 3 months after pediatric mild TBI from neuropsychological point of view. Whereas the incidence of psychiatric illness in children with mild TBI is significantly higher in 3 years after injury than in children without mild TBI [30], which means that the termination period of psychosocial outcome should be extended further compared with neuropsychological outcome.

In moderate and severe TBI, neuropsychological outcome has been evaluated over a longer period of time, from about 6 months [31] to 15 years [32] after injury. While most of promising cases reach a neuropsychological plateau about 1 year after injury [33], performance IQ improves gradually over 5 years after injury [34]. Another study reports that verbal IQ is rather getting worse over 14 years after injury because of drop-out from normal cognitive and academic development [35]. As an evidence to support the last report, meta-analysis of 28 reports by Babikian [36] shows that somewhat severely disabled cases, whose neuropsychological status being poor from the beginning of return to school, tend to dissociate and lower their growth curve from normal development one, and such phenomenon has been called "grown into deficit" [37,38], which might induce the limitation of career choice and decrease in revenue when children with TBI become middle-aged [39].

As per psychosocial outcome, social adaptation proved to be no less relevant to severity of TBI. As a result of 10 years follow-up survey after injury [40], reflecting the possibility of different basis from neuropsychological outcome.

\section{Predictors of Higher Brain Dysfunction after TBI in School-aged Children}

Anderson suggested four domains Injury factors, Developmental factors, Pre-injury factors, and Environmental factors-to determine and classify predictors of outcome from pediatric TBI. Injury factors consist of severity (mild, moderate, severe), nature and location (diffuse or focal) and subsequent disability (post-traumatic epilepsy, speech/physical disability) [41]. Developmental factors consist of age at injury and developmental stage. Pre-injury factors consist of preinjury functioning (cognitive ability, personality), family factors (family functioning, parental mental health) and gender. Environmental factors consist of socioeconomic status and access to resources (educational, rehabilitation).

Predictors and period/item of evaluation are in response each other. For example memory and executive function proved to be significant predictors of academic achievement 1 year after TBI in preschool children [42], whereas it has been reported that abnormal computed tomography findings is a predictor of cognitive sequelae 1 year after mild TBI in school-aged children [43]. On the other hand clusteranalysis showed that best outcome 10 years after TBI had a cluster with children with moderate injuries, young age at injury, average socioeconomic status and high pre-injury adaptive function [44]. Timing of TBI in children was analyzed as a predictor of intellectual outcome to clarify which theory-"early plasticity theory" [45] or "early vulnerability theory" [46] is plausible in recovery after insult (The former proposes that younger brain has greater plasticity and leads to better recovery after insult, while the latter proposing that younger brain is more susceptible to damage and leads to more serious cognitive impairment). As a result, children injured in middle childhood 7 to 9 years proved to be most vulnerable among four groups, infancy from 0 to 2 years, preschool from 3 to 6 years, middle childhood as described and late childhood over 10 years [47]

\section{Rehabilitation for Higher Brain Dysfunction after TBI in School-aged Children}

Considering standardization for rehabilitative methods, it is desirable to unify evaluative tests for higher cognitive dysfunction in children with TBI under the shortage of standardized tests for children. As one of such trials pediatric impact, correlating well with standardized tests, was developed to evaluate easily children with mild TBI on PC system [48]. In Japan, for the similar purpose, provisional standard value of WMS-R, WCST, TMT and SLTA for children at 6-18 years old were determined [49].

There are four main matters to perform practically cognitive rehabilitation for school-aged children with TBI.

1. Improvement of cognitive impairment

2. Acquirement of compensatory maneuvers and Adjustment of environment

\section{Support for re-entry to school or finding employment}

4. Acceleration for understanding/acceptance of impairment to people concerned and support for parents. Prior to carry them out, however, start time/quality/duration of rehabilitation must be discussed.

As to start time, early intervention is recommended in moderate and severe TBI due to needs for physical management [50]. It has been reported that early intervention Randomized Clinical Trial (RCT) did not significantly improve social activity of children with mild TBI [51], while another early intervention by providing an information booklet reduced anxiety and lowered the incidence of ongoing problems such as post-concussion syndrome [52]. Similarly early online problemsolving intervention RCT for school-aged children (14-17 years old) with moderate and severe TBI proved to improve long-term executive function [53]. Several institutes in Japan also have been doing such trials as provision of information by booklets or pamphlets [54,55].

As to quality of rehabilitation it is hard to do meta-analysis for effectiveness of rehabilitative methods in children with TBI due to considerably less uniformity of evaluation and materials compared with trials in adults with TBI, but there are some reviews [56-62]. Among those 
reviews one of highly qualified clinical study (prospective, randomized, controlled, cohort study: level 1) reported that the TEACH ware TM program, designed to train 5 different skill areas (attention, memory and word retrieval, comprehension of abstract language, organization and reasoning/problem solving), was performed for children aged 1221 years with TBI for 8 weeks and resulted in significant improvement of word retrieval and problem solving/reasoning while no significant improvement of attention [63]. It should be noted that methylphenidate therapy proved to be effective for attention disturbance after TBI in children, often referred to secondary ADHD [64].

As to duration/quantity of rehabilitation, longer inpatient rehabilitation for children with moderate to severe TBI bring better functional outcome and higher percentage of reintegration in regular educational system [65], suggesting dose-response relationship between duration/quantity of rehabilitation and functional recovery.

Turning to support for parents, it is evidenced by RCT that psychological intervention for those whom having children with TBI and some other chronic disease, is beneficial to keep their mental health stable [66].

In Japan we do not have yet such highly qualified RCTs as described above performing in the United States, Australia, Canada and other advanced nations. Also quite few Japanese institutes performed active intervention for children with higher cognitive dysfunction after TBI. However, as one of characteristics in Japanese support system, education program by special support school/class has been tried in parallel with medical rehabilitation in order to reinforce the improvement for interpersonal relationship in adaptive behavior/communication disorder or acquirement of social skill [67].

\section{Basic Researches on Higher Brain Dysfunction after TBI in School-aged Children}

In experimental study rodent models of Controlled Cortical Impact (CCI) and Fluid Percussion (FP) have been established and widely adopted. Following the characterization of histopathological and functional squeal of experimental adult TBI in both models, studies for experimental juvenile TBI by same models have been gradually started since end of $20^{\text {th }}$ century. Recent study has reported that injured juvenile rats with cortical lesion cavity and less neurons in the CA1 field of the hippocampus showed significant dysfunction in spatial memory 6 months after insult [68], supporting long-term clinical outcome. In addition, another experimental research has shown that experiencedependent plasticity is disturbed in juvenile rats with FP injury and the ability to benefit from environmental enrichment following TBI is dependent on time after insult [69], suggesting possibly appropriate timing of clinical intervention for school-aged children with TBI.

Neuroimaging study has been on remarkable progress since the beginning of $21^{\text {st }}$ century due to development of various excellent neuroimaging methods, especially functional MRI [70]. One of the trials connecting neuroimaging and higher cognitive function has reported that children with frontotemporolimbic or diffuse damage demonstrated variable social outcomes impaired social-emotional functioning, no mutual friends, low peer acceptance ratings, rejection/ victimization in the classroom from their TBI [71].

Neurophysiological research is another potential method to find missing link between TBI, especially mild TBI without positive image findings, and higher brain dysfunction. Recent cross-sectional study for sport concussion by event-related potential has reported persistent deficits, lasting at least 6 months after insult, especially in adolescents [71].

\section{Future Issues and Prospects}

Compared with United States, enacting public law for TBI since 1996 and doing systematic clinical studies or constructing support systems in early stage, system making in our country has just been getting started. As to support for parents, for example, few local institutes, having tackled this problem prior to model project of support for those whom with higher cognitive dysfunction, are still leading this field in Japan while various organizations actively provides information on their websites [72-76] in the United States. Under such situation, however, we recently have got the estimated number of school-aged children from junior high school to college in need of support with higher brain dysfunction as about 7000 in Japan [77]. In addition, recent trial survey in Japan has got the questionnaire result that schoolaged children with higher cognitive dysfunction can be acceptable in some educational institutes in more than $90 \%$ of educational boards [78]. These two recent achievements show us that educational support system for school-aged children with higher brain dysfunction is being developed and will hopefully be completed near future in Japan.

On the other hand, we have no highly qualified RCT related to cognitive functional recovery in children with TBI so far in Japan. It is expected that multicenter clinical trial would be planned in the near future.

One of the recent topics hardly begun in Japan is higher brain dysfunction derived from cerebral concussion and post-concussion syndrome, belonging to mild TBI, in school-aged children. In abroad this theme has been discussed in comparatively early stage especially in the field of sports [79] and the number of the researches related to this theme is steadily increasing year after year [80-83]. We Japanese also might have potentially huge number of school-aged children suffering from symptoms after mild TBI, accounting for nearly $90 \%$ of children TBI cases. It has been reported that the symptoms including higher cognitive dysfunction are transient; diminishing within 4 weeks in most cases, nevertheless long-term outcome of such cases is still unknown, especially in repetitive concussion cases of children compared with athletes, or young adults [84]. We are expected to begin the research in this field in order to protect children's brains and keep them under better condition.

\section{Conclusion}

This article reviewed literatures related higher brain dysfunction after TBI in children, especially school-aged. So many people of various professions-psychiatrist, pediatrician, neurologist, neurosurgeon, neuropsychologist, neuroscientist, nurse, physical therapist, occupational therapist, speech therapist, school official, medical social worker, politician, and so on- having been involved in this theme because of its complexity. Their trials seem as if attempt of the mountain named "higher brain dysfunction after TBI in children" ascent by so many different parties through so many different climbing routes. Therefore we should be able to reach the summit and grasp the whole picture of this mountain more quickly and reliably if only we, different parties, communicate and collaborate each other.

Future fruition of the achievements of this theme depends on our unceasing information sharing and collaboration beyond professions, regions and nations. 


\section{References}

1. https://www.mhlw.go.jp/english/index.html

2. http://www.caa.go.jp/en/

3. Number of children in our country-Named after "Children's Day" -From 'Population Estimation' (2015).

4. http://esa.un.org/unpd/wpp/

5. Jennett B, Bond M (1975) Assessment of outcome after severe brain damage. Lancet 7905: 480-484.

6. Uniform Data System for Medical Rehabilitation (2006) The WeeFIM clinical guide.

7. Fulkerson DH, White IK, Rees JM, Baumanis MM, Smith JL, et al. (2015) Analysis of Long-term (median 10.5 years) outcomes in children presenting with traumatic brain injury. J Neurosurg Pediatr 16: 410-419.

8. Wechsler D (1951) Equivalent test and mental ages for WISC. J Consult Psychol 15: 381-384.

9. Naglieri JA, Das JP (1997) Cognitive Assessment System. Administration and scoring manual. Interpretive handbook.

10. Gioia G, Isquith PK, Guy SC, Kenworthy L (2000) Test review: Behavior rating inventory of executive function. Child Neuropsychology 6: 235-238.

11. Achenbach TM (1991) Manual for the child behavior checklist/4-18 and 1991 profile. Department of Psychiatry, University of Vermont.

12. Welner Z, Reich W, Herjanic B, Jung K, Amado H (1987) Reliability, validity and parent-child agreement studies of the Diagnostic Interview for Children and Adolescents (DICA). J Am Acad Child Adolesc Psychiatry 26: 649-653.

13. Chambers WJ, Puig-Antich J, Hirsch M, Paez P, Ambrosini P, et al. (1985) The assessment of affective disorders in children and adolescents by semistructured interview: Test-retest reliability of the Schedule for affective disorders and schizophrenia for school-age children, present episode version. Arch Gen Psychiatry 42: 696-702.

14. Max JE, Castillo CS, Lindgren SD, Arndt S (1998) The neuropsychiatric rating schedule: Reliability and validity. J Am Acad Child Adolesc Psychiatry 37: 297-304.

15. Barry CT, Taylor HG, Klein S, Yeats KO (1996) Validity of neurobehavioral symptoms reported in children with traumatic brain injury. Child Neuropsychology 2: 213-226.

16. Sparrow SS, Balla D, Cicchetti D (1984) The vineland adaptive behavior scales. Circle Pines. American Guidance Services.

17. Miller IW, Epstein NB, Bishop DS, Keitner GI (1985) The mcmaster family assessment device: Reliability and validity. J Marital Fam Ther 11: 345-356.

18. Burgess ES, Drotar D, Taylor HG, Wade SL, Stancin T, et al. (1999) The family burden of injury interview (FBII): Reliability and validity studies. J Head Trauma Rehabil 14: 394-405.

19. Deroggatis L, Melisaratos N (1983) The Brief Symptom Inventory: An introductory report. Psychol Med 13: 595-604

20. Anderson V, Brown S, Newitt H, Hoile H (2009) Educational, vocational, psychosocial and quality-of-life outcomes for adult survivors of childhood traumatic brain injury. J Head Trauma Rehabil 24: 303-312.

21. Thomas DG, Collins MW, Saladino RA, Frank V, Raab J, et al. (2011) Identifying neurocognitive deficits in adolescents following concussion. Acad Emerg Med 18: $246-254$

22. Fay TB, Yeats KO, Wade SL, Drotar D, Stancin T, et al. (2009) Predicting longitudinal patterns of functional deficits in children with traumatic brain injury. Neuropsychology 23: 271-282.

23. Catroppa C, Anderson V, Muscara F, Morse SA, Haritou F, et al. (2009) Educational skills: Long-term outcome and predictors following paediatric traumatic brain injury. Neuropsychol Rehabil 19: 716-732.

24. Hanten G, Li X, Newsome M, Swank P, Chapman S, et al. (2009) Oral reading and expressive language after childhood traumatic brain injury: Trajectory and correlates of change overtime: Prospective study. Topics in Language Disorders 29: 238-244.

25. Hanten G, Li X, Newsome M, Swank P, Chapman S, et al. (2009) Oral reading and expressive language after childhood traumatic brain injury: Trajectory and correlates of change overtime: Retrospective study. Topics in Language Disorders 29: 244-248.

26. Green L, Godfrey C, Soo C, Anderson V, Catroppa C (2013) A preliminary investigation into psychosocial outcome and quality-of-life in adolescents following childhood traumatic brain injury. Brain Inj 27: 872-877.

27. Watanabe S, Yonemoto K, Ohashi M, Hashimoto K, Miyano S (2003) Costeffective study in TBI rehabilitation. Jpn J Rehabil Med 40: 581-586.

28. Hung R, Carroll LJ, Cancelliere C, Coté P, Rummy P, et al. (2014) Systemic review of the clinical course, natural history, and prognosis for pediatric mild traumatic brain injury: Results of the international collaboration on mild traumatic brain injury prognosis. Arch Phys Med Rehabil 95: S174-S191.

29. Keightley ML, Coté P, Rummy P, Hung R, Carroll LJ, et al. (2014) Systemic review of mild traumatic brain injury in children: Results of the international collaboration on mild traumatic brain injury prognosis. Arch Phys Med Rehabil 95: S192-S200.

30. Massagli TL, Fann JR, Burington BE, Jaffe KM, Katon WJ, et al. (2004) Psychiatric illness after mild traumatic brain injury in children. Arch Phys Med Rehabil 85: 1428-1434

31. Anderson V, Le Brocque R, Iselin G, Eren S, Dob R, et al. (2012) Adaptive ability, behavior and quality of life pre and posttraumatic brain injury in childhood. Disabil Rehabil 34:1639-1647.

32. Halldorsson JG, Arnkelsson GB, Tomasson K, Flekkoy KM, Hulda Bra Magnadottir, et al. (2013) Long-term outcome of medically confirmed and selfreported early traumatic brain injury in two nationwide samples. Brain Inj 27 : 1106-1118.

33. Irikura K, Miyasaka Y, Kurata A, Morii S, Yada K, et al. (1991) Long-term outcome after severe diffuse brain injury in children. Neurotraumatology 14 71-76

34. Kurihara M, Kohagizawa T, Etoh Y (2002) Diffuse axonal injury (DAI) in children: Prognosis and problems of higher cortical dysfunction. Jpn J Rehabil Med 39 648-654.

35. Jonsson CA, Horneman G and Emanuelson I (2004) Neuropsychological progress during 14 years after severe traumatic brain injury in childhood and adolescence. Brain Inj 18: 921-934.

36. Babikian T, Asarnow R (2009) Neurocognitive outcomes and recovery after pediatric TBI: Meta-analytic review of the literature. Neuropsychology 23 283-296.

37. Giza CC, Prins ML (2006) Is being plastic fantastic? Mechanism of altered plasticity after developmental traumatic brain injury. Dev Neurosci 28: 364-379.

38. Anderson V, Spencer-Smith M, Wood A (2011) Do children really recover better? Neurobehavioural plasticity after early brain insult. Brain 134: 2197 2221.

39. Nybo T, Sainio M, Muller K (2005) Middle age cognition and vocational outcome of childhood brain injury. Acta Neurol Scand 112: 338-342.

40. Anderson V, Godfrey C, Rosenfeld JV, Catroppa C (2012) 10 years outcome from childhood traumatic brain injury. Int J Dev Neurosci 30: 217-224.

41. Anderson V, Catroppa C (2006) Advances in postacute rehabilitation after childhood acquired brain injury: A focus on cognitive, behavioral and social domains. Am J Phys Med Rehabil 85: 767-777.

42. Fulton JB, Yeates KO, Taylor HG, Walz NC, Wade SL (2012) Cognitive predictors of academic achievement in young children 1 year following traumatic brain injury. Neuropsychology 26: 314-322.

43. Levine HS, Hanten G, Roberson G, Li x, Ewing-Cobbs L, et al. (2008) Prediction of cognitive sequelae based on abnormal computed tomography findings in children following mild traumatic brain injury. J Neurosurg Pediatrics 1: 461-470.

44. Jonsson CA, Catroppa C, Godfrey C, Smedler AC, Anderson V (1975) Individual profiles of predictors and their relations to 10 years outcome after childhood traumatic brain injury. Brain inj 27: 831-838.

45. Teuber HL (1975) Recovery of function after brain injury in man. Ciba Found Symp 34: 159-190. 
46. Kriel R, Krach L, Panser L (1989) Closed head injury: Comparison of children younger and older than 6 years of age. Pediatr Neurol 5: 296-300.

47. Crowe LM, Catroppa C, Babl FE, Rosenfeld JV, Anderson V (2012) Timing of traumatic brain injury in childhood and intellectual outcome. J Pediatr Psychol 37: 745-754.

48. Newman JB, Reesman JH, Vaughan CG, Gioia GA (2013) Assessment of processing speed in children with mild TBI: A "First Look" at the Validity of Pediatric ImPACT. Clin Neuropsychol 27: 779-793

49. Ehara M, Takahashi N, Yamazaki M, Akagi T (2006) Developmental changes of cognitive function in children: A preliminary study of assessment batteries for children with higher brain dysfunction. Jpn J Rehabil Med 43: 249-258.

50. Kochanek PM, Carney N, Adelson PD, Ashwal S, Bell MJ, et al. (2012) Guidelines for the acute medical management of severe traumatic brain injury in infants, children and adolescents--second edition. Pediatr Crit Care Med 13: S1-82.

51. Matuseviciene G, Eriksson G, DeBoussard CN (2015) No effect of an early intervention after mild traumatic brain injury on activity and participation: A randomized controlled trial. J Rehabil Med 48: 19-26.

52. Ponsford J, Willmott C, Rothwell A, Cameron P, Ayton G, et al. (2001) Impact of early intervention on outcome after mild traumatic brain injury in children. Pediatrics 108: 1297-1303.

53. Kurowski BG, Wade SL, Kirkwood MW, Brown TM, Stancin T, et al. (2014) Long-term benefits of an early online problem-solving intervention for executive dysfunction after traumatic brain injury in children : A randomized trial. JAMA Pediatr 168: 523-531.

54. http://www.kanariha-hp.kanagawarehab.or.jp/img/uploads/2/20100212105251. pdf.

55. http://www.chiba-reha.jp/artis-cms-files/20120409-193202-1750.pdf

56. Ylvisaker M, Feeney $\mathrm{T}$ (2002) Executive functions, self-regulation and learned optimism in pediatric rehabilitation: A review and implications for intervention. Pediatr Rehabil 5: 51-70.

57. Laatsch L, Harrington D, Hotz G, Marcantuono J, Mozzoni MP, et al (2007) An evidence-based review of cognitive and behavioral rehabilitation treatment studies in children with acquired brain injury. J Head Trauma Rehabil 22: 248-256.

58. Galvin J, Mandalis A (2009) Executive skills and their functional implications: Approaches to rehabilitation after childhood TBI. Dev Neurorehabil 12: 352-360.

59. Slomine B, Locascio G (2009) Cognitive rehabilitation for children with acquired brain injury. Dev Disabil Res Rev 15:133-143.

60. Gordon AL, di Maggio A (2012) Rehabilitation for children after acquired brain injury: Current and emerging approaches. Pediatr Neurol 46: 339-344

61. Backeljauw B, Kurowski BG (2014) Intervention for attention problems after pediatric traumatic brain injury:what is the evidence? PMR 6: 814-824.

62. Winkler R, Taylor NF (2015) Do children and adolescents with mild traumatic brain injury and persistent symptoms benefit from treatment? A systemic review. J Head Trauma Rehabil 30: 324-333.

63. Thomas-Stonell N, Johnson P, Schuller R, Jutai J (1994) Evaluation of a computer-based program for remediation of cognitive-communication skills. J Head Trauma Rehabil 9: 25-37.

64. Mahalik DM, Carmel PW, Greenberg JP, Molofsky W, Brown JA, et al. (1998) Psychopharmacologic treatment of acquired attention disorders in children with brain injury. Pediatr Neurosurg 29: 121-126.
65. Shaklai S, Peretz R, Spasser R, Simantov M, Groswasser Z (2014) Long-term functional outcome after moderate-to-severe paediatric traumatic brain injury. Brain Inj 28: 915-921.

66. Eccleston C, Fisher E, Law E, Bartlett J, Palermo TM (2015) Psychological interventions for parents of children and adolescents with chronic illness Cochrane Database Syst Rev 15: CD009660.

67. Kurihara M, Kohagizawa T, Eto $Y$ (2005) Support for re-entrance to school in children with acquired brain injury according to clinical pass development. Jpn J Rehabil Med 42: 131-137.

68. Kamper JE, Pop V, Fukuda AM, Ajao DO, Hartman RE, et al. (2013) Juvenile traumatic brain injury evolves into a chronic brain disorder: Behavioral and histological changes over 6 months. Exp Neurol 250: 8-19.

69. Giza C, Griesbach GS, Hovda DA (2005) Experience-dependent behaviora plasticity is disturbed following traumatic brain injury to the immature brain Behav Brain Res 157: 11-22.

70. Dennis M, Simic N, Bigler ED, Abildskov T, Agostino A, et al. (2013) Cognitive, affective, and conative theory of mind(ToM) in children with traumatic brain injury. Dev Cogn Neurosci 5: 25-39.

71. Bigler ED, Yeates KO, Dennis M, Gerhardt CA, Rubin KH, et al. (2013) Neuroimaging and social behavior in children after traumatic brain injury: Findings from the Social Outcomes of Brain Injury in Kids (SOBIK) study. NeuroRehabilitation 32: 707-720.

72. www.aans.org

73. http://biausa.org/brain-injury-children.htm

74. https://www.braintrauma.org/coma

75. http://www.cdc.gov/TraumaticBrainlnjury/data/index.html

76. www.ninds.nih.gov

77. Nakajima Y (2014) A study on the promotion of social participation support of higher brain dysfunction. Health, Labour and Welfare scientific research "Research on the promotion of social participation support of higher brain dysfunction" in 2013 fiscal year overall, sharing research report.

78. Niihira S, Kusaka N, Moriyama T (2015) Pilot study on the education of students with higher brain dysfunction. Journal of National Institute of Special Needs Education 4: 12-17.

79. Giza CC, Kutcher JS, Ashwal S, Barth J, Getchius TS, et al. (2013) Summary of evidence-based guideline update: evaluation and management of concussion in sports: Report of the Guideline Development Subcommittee of the American Academy of Neurology. Neurology 80: 2250-2257.

80. Nylander I, Rydelius PA (1998) Post-concussion syndrome: Brain damage constitutional characteristics and environmental reactions. Acta Paediatr Scand 77: 475-477

81. Willer B, Dumas J, Hutson A, Leddy J (2004) A population based investigation of head injuries and symptoms of concussion of children and adolescents in schools. Inj Prev 10: 144-148.

82. Grubenhoff JA, Kirkwood MW, Deakyne S, Wathen J (2011) Detailed concussion symptom analysis in a paediatric ED population. Brain Inj 25: 943-949.

83. Olsson KA, Lloyd OT, Lebrocque RM, Mckinlay L, Anderson VA, et al. (2013) Predictors of child post-concussion symptoms at 6 and 18 months following mild traumatic brain injury. Brain Inj 27: 145-157.

84. Bailes JE, Petraglia AL, Omalu BI, Nauman E, Talavage T (2013) Role of subconcussion in repetitive mild traumatic brain injury: a review. J Neurosurg 119: $1235-1245$. 